\title{
O PERFIL DAS OPERAÇÕES DE FUSÕES E AQUISIÇÕES NO BRASIL NO PERÍODO DE 2007 A 2012
}

Antônio Augusto Brion CARDOSO ${ }^{1}$

Maria Aparecida CURI ${ }^{2}$

\author{
${ }^{1}$ Universidade Federal de Juiz de Fora - Campus Governador Valadares. augusto.brion@ufjf.edu.br \\ ${ }^{2}$ Universidade Federal de Alfenas. macuri@ig.com.br.
}

\section{Recebido em: 28/11/2015 - Aprovado em: 18/07/2016 - Disponibilizado em: 18/12/2016}

\begin{abstract}
RESUMO:
O objetivo deste estudo foi caracterizar e analisar o volume de operações de fusões e aquisições ocorridas no Brasil Além disso, buscou-se identificar os setores da economia mais afetados e os países com os quais a movimentação dos negócios foi mais frequiente, com destaque para as transações de internacionalização das empresas brasileira. Assim, realizou-se um estudo descritivo que utilizou dados secundários para analisar as transações de fusões e aquisições no período compreendido entre os anos de 2007 a 2012. Os resultados apontam para uma consolidação dessas operações no mercado brasileiro, sendo o setor de tecnologia da informação aquele que mais incorreu em operações. Os EUA representa o país com mais representatividade nos negócios com o Brasil, no entanto o movimento de internacionalização de empresas brasileira apresentou um recuo, com investimentos em proporção contrária aos demais tipos de transações.
\end{abstract}

Palavras-chave: Fusão e aquisição, internacionalização de empresas, setores da economia

\begin{abstract}
:
The aim of this study was to characterize and analyze the volume of occurring mergers and acquisitions in Brazil also sought to identify the sectors most affected economy and the countries with which the business movement was more frequent, especially for the internationalization of Brazilian companies transactions. Thus, there was a descriptive study that used secondary data to analyze mergers and acquisitions transactions in the period between the years 2007 to 2012 . The results point to a consolidation of these operations in the Brazilian market, and the information technology sector one that incurred operations. The US is the country with more representation in business with Brazil, but the Brazilian companies internationalization movement had a setback with investments in reverse proportion to other types of transactions.
\end{abstract}

Keywords: Merger and acquisition, internationalization of companies, sectors of the economy

\section{Introdução}

Muitos são os motivos que levam as empresas a decidirem por novos investimentos. Um dos principais é a perspectiva de crescimento dos negócios. Levando-se em conta que os gestores de uma empresa tomam a decisão estratégica de expandir seu market share ou diversificar suas operações, há dois caminhos possíveis: o crescimento interno, ou as fusões ou aquisições. (PATROCÍNIO et al. 2007).

As fusões e aquisições constituem uma das atividades de destaque que proporciona nova configuração nas relações empresariais e são vistas pela teoria neoclássica como uma resposta na melhora da eficiência a alterações no ambiente econômico, como políticas antitrutes e desregulacão ou abertura de 
mercado, internacionalização, aumento da competição e maior integração dos mercados de capitais. (CAMARGOS e BARBOSA, 2009).

As últimas décadas do século $\mathrm{XX}$ foram marcadas por um aumento importante das operações de Fusões e Aquisições que envolveram empresas de diferentes países, setores de atividades e de porte variados. Esse movimento de evolução desse tipo de operações pode ser caracterizado como uma resposta estratégica das organizações ao competitivo ambiente empresarial, influenciado pelo processo de globalização.

No Brasil, somente foram incentivadas as operações de fusões e aquisições a partir das modificações realizadas na política econômica. O tema ganhou importância no início da década de 90 com a redução de entrada ao capital estrangeiro e a inserção do país no mercado global. A globalização modificou o funcionamento dos mercados, uma vez que acirrou a concorrência, obrigando as empresas a evoluírem, uma vez que as corporações transnacionais se expandem com grande velocidade (OLIVEIRA, RÊGO, 2011).

Diante do exposto, o estudo busca responder a seguinte pergunta: Qual o perfil das operações de fusões e aquisições efetivadas no Brasil?

Nesse sentido, o objetivo desse estudo é caracterizar e analisar o volume de operações de fusões e aquisições ocorridas no Brasil, no período compreendido entre os anos de 2007 a 2012, bem como identificar os setores da economia mais afetados e os países com os quais a movimentação foi mais freqüente, com destaque para as transações de internacionalização das empresas brasileira.

Tendo em vista a importância de se estudar a evolução do processo de fusões e aquisições no Brasil, este trabalho justifica-se na medida em que buscará concentrar esforços na geração de conhecimento relacionado ao suporte informacional no processo decisório das formas de fusões e aquisições no Brasil, atividade com poucos estudos empíricos, proporcionando subsídios para estudos futuros.

O artigo está estruturado da seguinte forma: inicialmente, é apresentada a introdução, seguida do referencial teórico, no qual, são abordados os temas: Fusões e aquisições; Internacionalização de empresas e Fusões e aquisições no Brasil; na seqüência, apresenta-se a metodologia utilizada para a realização da presente pesquisa e a análise e discussão dos resultados, encerrando-se com as considerações finais.

\section{Referencial teórico}

Os três eixos teóricos que informam o presente estudo são explorados, em termos de revisão de literatura, nas subseções a seguir. 


\subsection{Aquisições e fusões}

A relação entre empresa e ambiente é tão estreita que ao analisar o meio onde uma organização está inserida, é possível compreender as estratégias traçadas por cada uma delas, desta forma, é correto dizer que quanto mais turbulento for o ambiente, maior a necessidade que ela tem de se transformar, ou seja, maior a necessidade de se criar estratégias para minimizar os efeitos deste ambiente. $\mathrm{O}$ fato é que, manter-se isento de qualquer planejamento em um mercado altamente dinâmico é utopia. Matos (1981) atribui a instabilidade do mercado a da busca das organizações pelo crescimento, pois, para ele, esta busca proporciona situações de desequilíbrio, provocando assim, divergências de ideias, quebra de paradigmas e transformações na vida de pessoas e empresas.

De acordo Robbins (2006), no cenário atual existe poucos ambientes estáticos e a incerteza faz parte do mundo empresarial, sendo assim, o desempenho das organizações é ameaçado a todo o momento e como forma de driblar esta incerteza, estas programarão estratégias com intuito de minimizar os efeitos da instabilidade, transformando para isso, ameaças em oportunidades. Ainda segundo o autor, capacidade, volatilidade e complexidade são três dimensões fundamentais do ambiente de qualquer organização. Para ele, a capacidade dá condições de se identificar até onde se pode crescer e como sustentar este crescimento, a volatilidade indica o grau de instabilidade do mercado e a complexidade deve ser percebida através de dois fatores: o grau de heterogeneidade e concentração entre os elementos do ambiente, pois, um ambiente simples é homogêneo e concentrado, enquanto que um ambiente complexo tende a ser heterogêneo e disperso.

Neste ambiente turbulento e incerto, para muitas empresas, não crescer significa estar se extinguindo e Harrison (2005) apresenta que as táticas de crescimento adotadas pelas empresas diante de ambientes altamente dinâmicos estão relacionadas aos possíveis crescimentos, internos ou externos.

$\begin{array}{rrrr}\text { Para Godoy e Santos (2006) o } & \text { o } \\ \text { crescimento interno significa direcionar } & \text { o }\end{array}$ investimento para novas tecnologias e/ou para a busca por mercados em expansão e segundo eles, muitas empresas optam por este tipo de estratégia, pois possuem maior controle sobre a situação. Em contrapartida, esta expansão interna possui consideráveis limitações, como o tempo necessário para que a estratégia se traduza em lucros.

No caso da expansão externa, ela ocorre através de fusões e aquisições e conforme Godoy e Santos (2006), necessitam de uma carga maior de investimento e nem sempre seus resultados são os esperados, mas ainda assim, verifica-se que as fusões e 
aquisições tem uma representação importante nas estratégias de crescimento das firmas, pois elas são a forma rápida e eficiente de atingir um novo mercado.

Desta forma, pode-se verificar que as fusões e aquisições entre empresas têm sido comuns em diversos setores da economia ao redor do mundo.

Uma fusão é uma transação na qual uma firma, a adquirente, compra ações circulantes ou ativos de outra, assim denominada, alvo (DODD, 1980). Na Fusão ou consolidação as firmas envolvidas geralmente têm porte semelhante $\mathrm{e}$ combinam-se mediante uma simples permuta de ações, dando origem a outra firma, enquanto na aquisição ocorre a compra de uma firma por outra, e somente uma delas mantém

a identidade. (ROSS,WESTERFIELD e JAFFE, 1995).

Quadro 1 - Distinções básicas entre Fusão e Aquisição

\begin{tabular}{|c|c|}
\hline Fusão & Aquisição \\
\hline $\begin{array}{l}\text { Pode haver a criação de } \\
\text { uma nova } \\
\text { (consolidação). }\end{array}$ & $\begin{array}{l}\text { Uma das empresas } \\
\text { envolvidas geralmente } \\
\text { mantém a sua identidade } \\
\text { jurídica. }\end{array}$ \\
\hline $\begin{array}{l}\text { Geralmente a forma de } \\
\text { pagamento utilizada é uma } \\
\text { permuta de ações. }\end{array}$ & $\begin{array}{l}\text { A forma de pagamento } \\
\text { pode ser dinheiro, ações } \\
\text { ou outros títulos. }\end{array}$ \\
\hline $\begin{array}{l}\text { As firmas geralmente são } \\
\text { do mesmo setor, tem a } \\
\text { mesma atividade-fim. }\end{array}$ & $\begin{array}{lll}\text { É comum as } & \text { firmas } \\
\text { serem de } & \text { setores } \\
\text { diferentes. } & \\
\end{array}$ \\
\hline
\end{tabular}

Fonte: Camargos e Barbosa, 2003 adaptado pelos autores.

Segundo Camargos e Barbosa (2003) as origens da atividade de Fusões e Aquisições remontam ao final do século XVII e início do século XIX, quando a Revolução
Industrial desencadeou um processo de concentração de capitais e reestruturação sem precedentes, o qual, por meio de movimentos cíclicos, comumente conhecidos como ondas, vem definindo e caracterizando o sistema de produção predominante, o Capitalismo.

A evolução dos negócios mundiais, de acordo com Godoy e Santos (2006), parece demonstrarem que as empresas, enfrentam frequentemente a questão de que, se não estiver crescendo, estará extinguindo-se. Assim, uma empresa precisa escolher entre duas formas fundamentais de crescimento: expandir-se internamente ou optar pela expansão externa através de Fusões e Aquisições. Os objetivos desse processo de crescimento, na maioria das vezes estão relacionados com à geração de valor para o acionista por meio do aumento da competitividade da empresa.

Segundo Camargos e Barbosa (2010), a atividade de Fusões e Aquisições se dá em ondas, as quais aumentam e diminuem sua intensidade e seus impactos sobre a economia, o mercado de capitais ou os países nos quais ocorre, sem entretanto, reduzir os impactos e transformações que causam nas empresas envolvidas.

Os principais tipos de fusão ou aquisição, bem como os motivos para essas operações podem ser observados no quadro 2. 
Quadro 2 - Classificação das operações de fusões e aquisições

\begin{tabular}{|c|c|c|}
\hline Tipo & Descrição & Possíveis motivos \\
\hline 1. Horizontais & $\begin{array}{l}\text { União entre } \\
\text { firmas } \\
\text { atuantes no } \\
\text { mesmo ramo } \\
\text { de atividade, } \\
\text { geralmente } \\
\text { concorrentes; }\end{array}$ & $\begin{array}{ll}- & \text { Obter de } \\
& \text { economias de } \\
& \text { escala } \\
& \text { escopo } \\
-\quad & \text { Elevação do } \\
& \text { market-share } \\
- & \text { Penetrar } \\
& \text { rapidamente } \\
\text { em novas } & \text { regiões }\end{array}$ \\
\hline 2. Verticais & $\begin{array}{l}\text { Quando } \\
\text { resultam da } \\
\text { união entre } \\
\text { firmas que } \\
\text { fazem parte da } \\
\text { mesma cadeia } \\
\text { produtiva, } \\
\text { podendo ser } \\
\text { para cima } \\
\text { (montante), } \\
\text { em direção aos } \\
\text { fornecedores, } \\
\text { ou para baixo } \\
\text { (jusante), em } \\
\text { direção aos } \\
\text { distribuidores. }\end{array}$ & $\begin{array}{ll}- & \text { Maior } \\
\text { controle sobre } & \\
\text { as atividades } \\
- & \begin{array}{l}\text { Proteção do } \\
\text { investimento } \\
\text { principal }\end{array} \\
- & \text { Maior } \\
\text { facilidade na } \\
\text { distribuição } \\
\text { dos produtos } \\
\text { - Assegurar } \\
\text { matérias- } \\
\text { primas } \\
\text { (eventualment } \\
\text { e a custos } \\
\text { mais baixos) }\end{array}$ \\
\hline $\begin{array}{l}3 . \\
\text { Conglomerados }\end{array}$ & $\begin{array}{l}\text { Quando } \\
\text { envolvem } \\
\text { firmas em } \\
\text { ramos de } \\
\text { atividade não } \\
\text { relacionados, } \\
\text { cujo principal } \\
\text { objetivo, na } \\
\text { maioria das } \\
\text { vezes, é a } \\
\text { diversificação } \\
\text { de } \\
\text { investimentos, } \\
\text { visando a } \\
\text { reduzir riscos } \\
\text { a aproveitar } \\
\text { oportunidades } \\
\text { de } \\
\text { investimentos. }\end{array}$ & $\begin{array}{ll}- & \begin{array}{l}\text { Diversificação } \\
\text { do risco }\end{array} \\
- & \text { Aproveitar as } \\
\text { oportunidades } \\
\text { de } \\
\text { investimento }\end{array}$ \\
\hline
\end{tabular}

Fonte: Ross, Westerfield e Jaffe (1995); BNDES (1999) - adaptado pelos autores.

\subsection{Internacionalização}

Diversas teorias têm sido desenvolvidas no intuito de se determinar os diversos motivos para as fusões e aquisições internacionais como opção de crescimento. Não obstante ao estudo da criação de valor para os acionistas um exame acurado deve ser feito no sentido de se identificar as reais motivações para a utilização desta prática.

Barkema e Vermeulen, 1998; e Hennart e Park, 1993, apud Bhouthers \& Brouthers 2000, informam que uma vez que uma organização decide expandir sua participação de mercado pela via de fusões e aquisições internacionais há pelo menos duas decisões inerentes à internacionalização de suas atividades, quais seja a decisão sobre o percentual de participação no empreendimento estrangeiro, ou seja, até que ponto haverá penetração de mercado, ao que os autores nomeiam como decisão de modo de entrada.

A segunda decisão inerente ao processo de internacionalização das atividades se refere à escolha entre a criação de um novo empreendimento ou a aquisição de um já existente, ao que os autores nomeiam como escolha do modo de diversificação.

A aquisição internacional também está relacionada aos custos de transação, que são os custos relacionados à operação da organização em mercados estrangeiros e à eficiência das estruturas organizacionais alternativas, com as quais a empresa deverá compartilhar de seus ativos (MADHOK, 1997). 
Ainda relacionado ao custo de transação Brouthers \& Brouthers (2000) informam que em estudos relacionados aos investimentos diretos internacionais um aspecto a ser fortemente considerado é a capacidade tecnológica da empresa investidora, proporcionando vantagens competitivas sobre as firmas concorrentes locais no ambiente externo. Pode-se considerar a capacidade tecnológica, ou Know-How, como um ativo intangível, ou seja, as organizações realizam seus investimentos não apenas com a finalidade de expansão de seus mercados, mas, também, em busca do conhecimento residente.

Outro aspecto fundamental em aquisições internacionais está relacionado à marca. Wernerfelt, 1984, informa que a marca é um recurso de capital crucial às organizações, sendo um ponto crítico para o sucesso e penetração de mercado. A marca tem a potencialidade de ser utilizada para reduzir custos e aumentar as margens de contribuição. Tal fato, aliado à dificuldade de penetração de nova marca em mercados altamente competitivos, como o mercado norte americano, propiciam o ambiente ideal para aquisições internacionais.

A força de vendas ou equipe de vendas também é fator de grande impacto no que se refere à fusões e aquisições internacionais. Há grande demanda de tempo para a construção e manutenção dos sistemas de força de vendas, porque eles estão relacionadas a intrincadas redes sociais que exigem a adaptação do produto, do consumidor, e amos. Esta adaptação leva à criação de produtos altamente específicos, a desafios gerenciais que são agravados pela dificuldade de avaliação de desempenho (Anderson e Coughlan, 1987; apud Brouthers \& Brouthers, 2000).

\subsection{Fusões e aquisições no Brasil}

A década de 1990 representou o início de uma nova era econômica para o Brasil, que deixou de ser uma economia fechada e sem competitividade para se tornar uma economia aberta e globalizada, caracterizada principalmente pela redução da proteção tarifária. Esta política de abertura do mercado nacional apresentou ao mundo empresas com baixos níveis técnicos e tecnológicos o que pode ser considerado como o primeiro fator de atratividade de investimentos, porém, a instabilidade econômica e frágeis condições de infraestrutura inviabilizaram alguns investimentos estrangeiros de longo prazo.

O Plano Real de 1994 que se caracterizou como um plano para estabilização da moeda não só baseado em medidas emergenciais no âmbito da política monetária, mas também em medidas de efeito em longo prazo, ao insistir num processo de reformas estruturais como a da previdência social, a administrativa e mesmo a fiscal criou 
o novo cenário inserindo o Brasil no mundo globalizado. Este novo perfil econômico proporcionou o acesso a matérias primas, máquinas e equipamentos mais modernos e eficientes. Neste contexto, as fusões e aquisições representam um meio eficaz de as empresas obterem recursos para investimentos em novas tecnologias ou ainda para a adaptação de seu porte e estrutura ao mercado (CHAVES e SILVA, 2011)

Cano (2002) apresenta alguns dos fatores que influenciaram os processos de F\&A a partir de 1990 no Brasil: 1) reflexo das operações ocorridas na arena internacional devido ao seu caráter institucional; 2) retomada do processo de restruturação produtiva nacional proporcionada pelo investimento estrangeiro direto (IDE) que vislumbrou condições econômicas favoráveis e 3) busca pelas empresas nacionais e estrangeiras pela estratégia de F\&A, além da especialização do core business.

Miranda e Martins (2000) atribuem a crescente evolução dos processos de F\&A à necessidade estratégica que muitas empresas têm de globalizar a produção e suas finanças e segundo ele, pode-se aliar a este fator, o elevado nível de liquidez dessas empresas e bancos.

No Brasil, como em outras economias emergentes, o crescimento do número de fusões e aquisições acompanhou o processo de liberalização econômica. Esse fator, segundo Wood Jr., Vasconcelos e Caldas
(2004) favoreceu os processos de F\&A de três diferentes modos: primeiro, a desregulamentação dos mercados locais, associada às tendências internacionais em direção à globalização, permitiu que as empresas estrangeiras adquirissem empresas brasileiras; segundo, programas de privatização criaram oportunidades para que muitas empresas estrangeiras e brasileiras adquirissem grandes operações nos setores de energia, de telecomunicações e bancário; e terceiro, a elevada competição internacional, associada à acelerada mudança tecnológica, obrigou empresas domésticas a se fundirem ou a adquirirem umas às outra.

O gráfico 1 mostra a evolução do número de transações em aquisições e fusões ocorridas no Brasil, no período de 1994 a 2012.

Gráfico 1 - Evolução das transações de Fusões e aquisições no Brasil

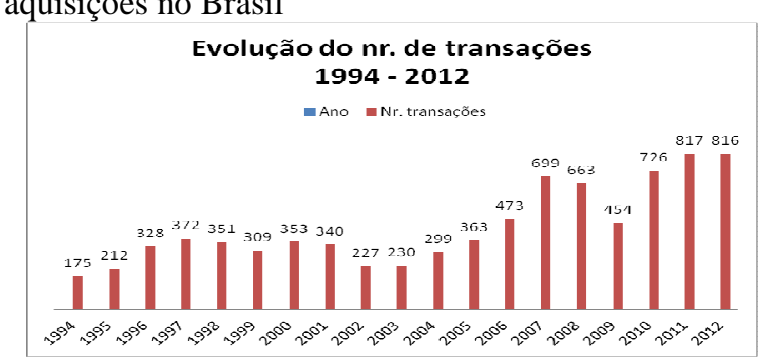

Fonte: KMPG, 2013

Como apresentado no gráfico 1, percebe-se um crescimento no número de incorporações, o que revela um movimento dos grupos empresariais em direção a maiores racionalização e concentração de suas atividades, visando a redução dos custos através de processos de combinação de negócios. A expressão Combinação de 
negócios (business combination) é utilizada para englobar todas as formas de junção de interesses. Os termos aquisição, fusão, incorporação e consolidação recebem definições técnicas, legais locais e internacionais diferentes, mas na prática são muitas vezes usados como sinônimos. O termo consolidação é usado na contabilidade para referir-se ao processo de apresentação aglutinada das Demonstrações Contábeis de uma empresa controladora e suas controladas, ou seja, um grupo de empresas sob o mesmo controle. (GODOYe SANTOS, 2006)

\section{Metodologia}

\subsection{Enquadramento Metodológico}

Os delineamentos desta pesquisa deram-se em função dos objetivos, dos procedimentos e da abordagem do problema. No que concerne aos objetivos, esta pesquisa consiste de um estudo do tipo descritivo. Tendo em vista o problema de pesquisa construído e considerando os objetivos deste trabalho, a pesquisa se caracteriza como descritiva uma vez que focaliza analisar o comportamento das operações de fusões e aquisições efetuadas no Brasil, durante o período compreendido entre os anos de 2007 a 2012. Para Gil (2009) a pesquisa descritiva tem como objetivo primordial a descrição das características de determinada população ou fenômeno ou o estabelecimento de relações entre variáveis.
Quanto aos procedimentos, a pesquisa caracteriza-se como bibliográfica e documental. Conforme Gil (2009), a pesquisa bibliográfica pode ser desenvolvida a partir de material já elaborado, constituído principalmente de livros e artigos científicos e a pesquisa documental, por valer-se de materiais que não receberam um tratamento analítico, ou que ainda podem ser reelaborados de acordo com os objetivos.

$\mathrm{Na}$ análise dos dados, utilizou-se a abordagem quali-quantitativa. Segundo Minayo (1999) o conjunto de dados qualitativo e quantitativo, não se opõem. Ao contrário, se complementam, pois a realidade abrangida por eles interage dinamicamente, excluindo qualquer dicotomia.

Em síntese, a pesquisa classifica-se como descritiva, utilizando como procedimento a pesquisa bibliográfica e documental, com abordagem qualiquantitativa dos dados.

\subsection{Procedimentos para coleta e análise de dados}

Para este estudo elegeu-se as operações de fusões e aquisições ocorridas no Brasil, por sua relevância no cenário econômico. Foram coletadas as informações, entre os anos de 2007 e 2012. Os dados foram extraídos dos Relatórios trimestrais publicados pela empresa de consultoria KPMG Corporate Finance, sem qualquer 
tratamento por parte dos pesquisadores. Este estudo compreende o volume de transações de fusões e aquisições classificadas em transações domésticas, aquelas ocorridas entre empresas de capital brasileiro, e transações cross border, que são as transações internacionais.

A análise de dados dividiu-se em três fases: na primeira, utilizou-se a divisão das operações de fusões e aquisições em transações domésticas e em transações Cross border, para os cinco setores de atividades com maior volume de operações em cada um dos anos analisados. A segunda fase contempla a identificação e análise do setor de atividades com maior presença no ranking de operações no período analisado. Por fim, relacionou-se as operações de internacionalização de empresas brasileiras com as operações totais ocorridas no mesmo período estabelecido.

\section{Discussão e Análise dos Resultados}

Nesse tópico serão analisadas as operações de fusões e aquisições que envolveram direta ou indiretamente empresas brasileiras. No quadro 3 , é demonstrado a evolução do volume total das operações de fusões e aquisições. As transações domésticas superaram o volume das transações cross border nos anos de 2007, 2008 e 2011, nos demais anos as transações cross border são superiores. Fica evidenciado que ocorreu o equilíbrio no volume por tipo de operações, ou seja, $48,72 \%$ do total das operações do período analisado foram provenientes de operações domésticas e $51,28 \%$ referem-se a operações cross border.

Quadro 3 - Evolução do volume de transações por tipo

\begin{tabular}{|c|c|c|c|}
\hline Ano & $\begin{array}{c}\text { Transações } \\
\text { Domésticas }\end{array}$ & $\begin{array}{c}\text { Cross } \\
\text { Border }\end{array}$ & Total \\
\hline 2007 & 351 & 348 & 699 \\
\hline 2008 & 379 & 284 & 663 \\
\hline 2009 & 219 & 235 & 454 \\
\hline 2010 & 333 & 393 & 726 \\
\hline 2011 & 410 & 407 & 817 \\
\hline 2012 & 342 & 474 & 816 \\
\hline
\end{tabular}

Fonte: Elaborado pelos autores a partir de KPMG (2007;2012)

O movimento de fusões e aquisições no Brasil, no período analisado, aponta os setores da economia que mais buscaram a consolidação de seus negócios, com a intensificação de operações no Brasil e no mundo.

Quadro 4: Setores de atividades com maior volume de transações de fusões e aquisições

\begin{tabular}{|c|l|c|c|c|}
\hline \multirow{2}{*}{ Ano } & \multicolumn{1}{|c|}{$\begin{array}{c}\text { Setor de } \\
\text { Atividades }\end{array}$} & \multicolumn{2}{|c|}{ Transações } & \multirow{2}{*}{ Total } \\
\cline { 3 - 4 } & $\begin{array}{l}\text { Alimentos, } \\
\text { bebidas e fumo }\end{array}$ & $\begin{array}{c}\text { Cross } \\
\text { Border }\end{array}$ & \\
\hline $\begin{array}{l}\text { Tecnologia da } \\
\text { Informação } \\
\text { Imobiliário }\end{array}$ & 29 & 37 & 66 \\
& $\begin{array}{l}\text { Shopping center } \\
\text { Produtos } \\
\text { Químicos e } \\
\text { Petroquímicos }\end{array}$ & 47 & 4 & 56 \\
\hline \multirow{2}{*}{2008} & $\begin{array}{l}\text { Tecnologia da } \\
\text { Informação } \\
\text { Alimentos, } \\
\text { bebidas e fumo } \\
\text { Educação }\end{array}$ & 48 & 25 & 51 \\
\hline
\end{tabular}




\begin{tabular}{|c|c|c|c|c|}
\hline & $\begin{array}{l}\text { Imobiliário } \\
\text { Mineração }\end{array}$ & $\begin{array}{c}30 \\
9\end{array}$ & $\begin{array}{l}11 \\
18\end{array}$ & $\begin{array}{l}41 \\
27\end{array}$ \\
\hline \multirow{5}{*}{2009} & $\begin{array}{l}\text { Tecnologia da } \\
\text { Informação }\end{array}$ & 35 & 23 & 58 \\
\hline & $\begin{array}{l}\text { Alimentos, } \\
\text { bebidas e fumo }\end{array}$ & 13 & 26 & 39 \\
\hline & Seguros & 12 & 12 & 24 \\
\hline & Imobiliário & 12 & 11 & 23 \\
\hline & $\begin{array}{l}\text { Telecomunicaçõe } \\
\text { s e Mídia }\end{array}$ & 10 & 13 & 23 \\
\hline \multirow{5}{*}{2010} & $\begin{array}{l}\text { Tecnologia da } \\
\text { Informação }\end{array}$ & 44 & 41 & 85 \\
\hline & $\begin{array}{l}\text { Alimentos, } \\
\text { bebidas e fumo }\end{array}$ & 18 & 24 & 42 \\
\hline & Imobiliário & 38 & 3 & 41 \\
\hline & $\begin{array}{l}\text { Companhias } \\
\text { energéticas }\end{array}$ & 15 & 20 & 35 \\
\hline & Petróleo e Gás & 9 & 25 & 34 \\
\hline \multirow{5}{*}{2011} & $\begin{array}{l}\text { Tecnologia da } \\
\text { Informação }\end{array}$ & 45 & 45 & 90 \\
\hline & $\begin{array}{l}\text { Telecomunicaçõe } \\
\text { s e Mídia }\end{array}$ & 24 & 35 & 59 \\
\hline & Imobiliário & 32 & 14 & 46 \\
\hline & $\begin{array}{l}\text { Alimentos, } \\
\text { bebidas e Fumo }\end{array}$ & 25 & 19 & 44 \\
\hline & $\begin{array}{l}\text { Companhias } \\
\text { energéticas }\end{array}$ & 21 & 21 & 42 \\
\hline \multirow{5}{*}{2012} & $\begin{array}{l}\text { Tecnologia da } \\
\text { Informação }\end{array}$ & 38 & 66 & 104 \\
\hline & $\begin{array}{l}\text { Serviços para } \\
\text { empresas }\end{array}$ & 19 & 46 & 65 \\
\hline & $\begin{array}{l}\text { Empresas de } \\
\text { internet }\end{array}$ & 12 & 44 & 56 \\
\hline & $\begin{array}{l}\text { Alimentos, } \\
\text { bebidas e fumo }\end{array}$ & 18 & 28 & 46 \\
\hline & Shopping center & 24 & 12 & 36 \\
\hline
\end{tabular}

Fonte: Elaborado pelos autores a partir de KPMG (2007;2012)

O ranking setorial de transações, formado por quarenta e três setores de atividade, destaca os cinco setores com maior volume de transações, como é demonstrado no quadro 4. O segmento de Tecnologia da Informação (TI) liderou o ranking setorial desde o ano de 2008, e suas transações doméstica, 239 no período, superaram o volume de 227 transações do tipo cross border de um total de 466 transações. Os setores que se destacam na sequência são: alimentos, bebidas e fumo, imobiliário, Shopping Center e Telecomunicações Mídia.

O gráfico 2 demonstra o volume de transações por setores acumulado no período em análise. Com exceção do setor de alimentos, bebidas e fumo, os demais setores realizaram mais transações domésticas do que transações cross border.

Gráfico 2: Evolução do volume de Transações por setores econômicos

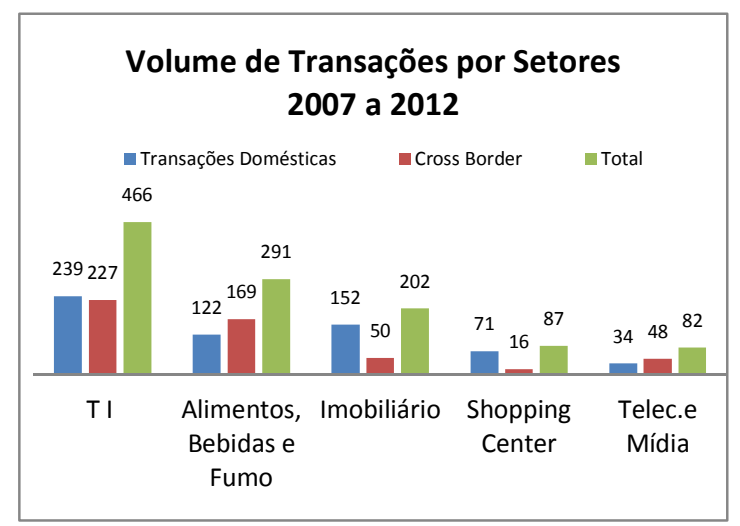

Fonte: Elaborado pelos autores a partir de KPMG (2007; 2012)

$\mathrm{Na}$ análise de participação dos países, os Estados Unidos aparece como o principal país com o qual o Brasil incorreu nas operações de fusões e aquisições. No quadro 5 apresenta-se três operações que caracterizam tipos de negócios realizados no período em análise bem como a indicação dos cinco países que com maior volume de transações. As operações em que as empresas brasileiras investem em empresas estrangeiras no Brasil e/ou no exterior tiveram maior participação dos Estados Unidos, seguido da 
Argentina, Espanha, México e Colômbia.

Para as operações que envolveram a entrada de capital estrangeiro no Brasil e para as que envolveram a saída de capital estrangeiro do Brasil, os Estados Unidos aparece como líder no número de transações.

Quadro 5: Países com maior frequência nas operações de fusões e aquisições

\begin{tabular}{|l|l|l|l|l|l|}
\hline Operações & \multicolumn{2}{|c|}{ Países com maior volume de transações no } \\
período & & \\
\hline $\begin{array}{l}\text { Empresas } \\
\text { Brasileiras } \\
\text { investindo } \\
\text { em } \\
\text { empresas } \\
\text { estrangeiras } \\
\text { no Brasil } \\
\text { e/ou no } \\
\text { exterior }\end{array}$ & EUA & Argentina & Espanha & México & Colômbia \\
\hline $\begin{array}{l}\text { Envolvendo } \\
\text { a entrada de } \\
\text { capital } \\
\text { estrangeiro } \\
\text { no Brasil }\end{array}$ & EUA & França & Reino & Alemanha & Canadá \\
\hline $\begin{array}{l}\text { Envolvendo } \\
\text { a saída de } \\
\text { capital } \\
\text { estrangeiro } \\
\text { do Brasil }\end{array}$ & EUA & Alemanha & França & Espanha & Reino \\
\hline
\end{tabular}

Fonte: Elaborado pelos autores a partir de KPMG $(2007 ; 2012)$

Um destaque oportuno diz respeito ao volume de operações em que se busca a internacionalização de empresas, ou seja, operações em que empresas de capital majoritário brasileiro adquiri de estrangeiros, capital de empresa estabelecida no exterior.

Quadro 6: Volume de Internacionalização de empresas brasileiras

\begin{tabular}{|l|r|r|r|r|r|r|}
\hline Ano & 2007 & 2008 & 2009 & 2010 & 2011 & 2012 \\
\hline $\begin{array}{l}\text { Total } \\
\text { Transação }\end{array}$ & 699 & 663 & 454 & 726 & 817 & 816 \\
\hline $\begin{array}{l}\text { Nr. } \\
\begin{array}{l}\text { Internacional } \\
\text { ização de } \\
\text { empresas }\end{array}\end{array}$ & 66 & 58 & 31 & 65 & 56 & 37 \\
\hline $\begin{array}{l}\text { Percentual } \\
(\%)\end{array}$ & 9,44 & 8,75 & 6,83 & 8,95 & 6,85 & 4,53 \\
\hline
\end{tabular}

Fonte: Elaborado pelos autores a partir de KPMG (2007;2012)
No quadro 6, pode-se verificar o volume, de operações que representam a participação de empresa brasileiras como protagonistas nos negócios. No ano de 2007 ocorreu uma participação mais significativa com $9,44 \%$ do total das operações de fusões e aquisições No ano de 2012 apresenta-se o menor percentual de participações, 4,53\%. Apesar de as operações totais terem se mantido no mesmo patamar de 2011, percebe-se um recuo de 33,9\% na operações de internacionalização de empresas que passou de 56 em 2011 para 37 em 2012.

\section{Considerações finais}

As mudanças significativas ocorridas no Brasil na década de 1990 proporcionaram a inserção do Brasil no mercado global. Criou-se um novo ambiente econômico, tornando-se essencial a transformação das estruturas empresariais nacionais. Diversos setores da economia rumam claramente para a consolidação, com a intensificação de operações de fusão e aquisição de empresas no Brasil e no mundo.

O objetivo deste estudo, foi o de caracterizar e analisar o volume de operações de fusões e aquisições ocorridas no Brasil, no período compreendido entre os anos de 2007 a 2012, bem como identificar os setores da economia mais afetados e os países com os quais a movimentação dos negócios foi mais 
freqüente, com destaque para as transações de internacionalização das empresas brasileiras.

Os resultados demonstram que houve um equilíbrio no volume de operações por tipo, ou seja, $48,72 \%$ do total das operações do período analisado foram provenientes de operações domésticas e 51,28\% referem-se a operações cross border. Os setores da economia que se destacaram com maior volume de transações foram: tecnologia da informação; alimentos, bebidas e fumo: imobiliário; shopping Center e telecomunicações e mídia. Os EUA aparece como o principal país com o qual o Brasil incorreu em todos os tipos de transações de

\section{Referências Bibliográficas}

BNDES. Fusões e aquisições no setor de alimentos. Informe Setorial, abr. 1999. Disponível em: <http://www.bndes.gov.br/conhecimento/setorial/gs1_1 5.pdf>. Acesso em: 09 março 2013.

BROUTHERS, K.D.; BROUTHERS, L.E. Acquisition or greenfield start-up? Institutional, cultural and transaction cost influences. Strategic Management Journal; Jan 2000; 21, 1; ABI/INFORM Global pg. 89

CAMARGOS, M.A.: BARBOSA, F.V. Fusões, Aquisições e Takeovers: Um levantamento teórico dos motivos, hipóteses testáveis e evidências empíricas. Caderno de Pesquisas em Administração, São Paulo, V.10, nr. 2 p. 17-38, abril/junho 2003

Fusões e

Aquisições de Empresas Brasileiras: Sinergias Operacionais. Revista de Administração de Empresas, São Paulo SP. V.49, nr.2 P. 206-220, abr/jun, 2009.

Fusões e

Aquisições de Empresas Brasileiras: Sinergias Operacionais, Gerenciais e Rentabilidade. Revista Contabilidade Vista e Revista UFMG, Belo Horizonte MG. V.21, nr. P. 69-99, jan/mar 2010. fusões e aquisições. A análise de operações de internacionalização das empresas brasileiras revela que houve um declino no volume de operações, partindo de um percentual de 9,44\% do montante das operações no ano de 2007, com queda nos anos seguinte, e em 2012 essa participação representou 4,53\% .

Cabe ressaltar, por fim, que as evidências encontradas neste estudo demonstram o perfil das operações de fusões e aquisições ocorridas no Brasil, e que dessa forma podem contribuir no sentido de apontar tendências do ambiente de negócios e a desenvolver instrumentos mais sofisticados para avaliar os novos movimentos do universo corporativo.

CANO, M. O recente processo de fusões e aquisições na economia brasileira. $164 \mathrm{f}$. Dissertação de Mestrado em Economia, Instituto de Economia, Universidade Estadual de Campinas, Campinas, 2002.

CHAVES,P.A; SILVA, P.R.C. Fusões e Aquisições. In: SILVA, P.R.C. (Org) Doing Business In Brazil Legal Guidelines And Main Industries, Belo Horizonte MG, 2011 p. 92-107

DODD, P. Meger proporsal, management discrition and stockholder wealth. Journal of financial Economics, Amsterdam: North Holland, v.8, n.2, p. 105-137, Jun. 1980

GIL, Antonio Carlos. Métodos e Técnicas de Pesquisa Social. 6 ed. 2. Reimpressão. São Paulo: Atlas, 2009.

GODOY, Carlos Roberto de ; SANTOS, Ariovaldo dos . Contabilidade para Fusões e Aquisições de Empresas: soluções históricas para problemas contemporâneos. RAUSP. Revista de Administração, v. 41, p. $29-42,2006$.

HARRISON, Jeffrey S. Administração estratégica de recursos e relacionamentos. Porto Alegre: Bookman, 2005. 
KPMG, Corporate Finance. Pesquisa de Fusões e Aquisições. 2007-2012 (por trimestre). Disponível em <http://www.kpmg.com.br/publicacoes_fas.asp?ft=5\&f $\mathrm{x}=16>$. Acesso em 09 de março de 2013.

MADHOK, A. Cost, value and foreign market entry mode: the transaction na the firm. Strategic Management Journal, p. 39-61. 1997.

MATOS, Francisco G. de. Administração para crescimento empresarial: habilidades gerenciais e desenvolvimento organizacional. Rio de Janeiro: Livros Técnicos e Científicos, 1981.

MINAYO, Maria Cecília de Souza. Ciência, Técnica e Arte: o Desafio da Pesquisa Social. In: MINAYO, Maria Cecília de Souza (Org.) Pesquisa Social:

Teoria, Método e Criatividade. 14 ed. Rio de Janeiro: Vozes, 1999.

MIRANDA, José Carlos: MARTINS, Luciano. Fusões e Aquisições de empresas no Brasil. Economia e Sociedade, V.14, p.67-88, 2000.

OLIVEIRA, A. B de: RÊGO, R. B. O Papel da Sinergia nas Decisões de Fusões e Aquisições. Um
Estudo de Caso da Criação da Ambev à Imbev. Relatórios de Pesquisa em Engenharia de Produção, V.11 n1. Niterói, 2011

PATROCÍNIO,M.R; KAYO, E.K.; KIMURA, H. Intangibilidade e criação de valor nos eventos de fusão e aquisição: uma análise dos retornos anormais no período de 1994 a 2004. R.Adm., São Paulo, v.42, n.2, p.205-215, abr./maio/jun. 2007

ROBBINS, Stephen Paul. Administração: mudanças e perspectivas. São Paulo: Saraiva, 2006.

ROSS, S.A; WESTERFIELD, R.W.; JAFFE, J.F. Administração Financeira: corporate finance. São Paulo: Atlas, 1995. 670p.

WERNERFELT, B.A reseource-basead view of the firm. Strategic Management Journal, p. 171-180, 1984.

WOOD JUNIOR, Thomaz; VASCONCELOS, Flávio C.; CALDAS, Miguel P. Fusões e aquisições no Brasil. RAE Executivo, São Paulo, v. 2, n. 4, nov. 2003/jan. 2004. 